\title{
Patient satisfaction with clinical laboratory services and associated factors among adult patients attending outpatient departments at Debre Markos referral hospital, Northwest Ethiopia
}

\author{
Asmamaw Alelign ${ }^{1}$ and Yihalem Abebe Belay ${ }^{2^{*} \text { (D) }}$
}

\begin{abstract}
Objectives: There is limited evidence on patient satisfaction with clinical laboratory services in Northwest Ethiopia. This study aimed to assess patient satisfaction with clinical laboratory services and associated factors among adult patients attending outpatient departments at Debre Markos hospital, Northwest Ethiopia. Cross-sectional study was conducted among 391 patients from April 09-16, 2019 using interviewer-administered questionnaire. Systematic random sampling technique was used. Data were entered into Epi-Data software version 4.2, and analyzed using SPSS 23. Binary logistic regression analysis was employed. Variables having $p$-value $<0.05$ were considered as statistically significant.

Results: Overall level of patient satisfaction towards clinical laboratory services was $48.3 \%$. Patients with no occasion of missing laboratory results [AOR: $2.10 ; 95 \% \mathrm{Cl}(1.13,3.83)]$, had diplomas and above educational level [AOR: $0.38 ; 95 \%$ $\mathrm{Cl}(0.15,0.96)]$, and who reported no place in the laboratory to put personal things [AOR: $0.37 ; 95 \% \mathrm{Cl}(0.21,0.54)]$ were significant factors. Hospital administration and laboratory department in Debre Markos hospital should strengthen their effort to improve patient satisfaction focusing on educational status of patients, missing laboratory results, and the availability of places to put personal things in the blood drawing room.
\end{abstract}

Keywords: Debre Markos hospital, Patient satisfaction, Laboratory services

\section{Introduction}

Patient satisfaction is a crucial and commonly used indicator for measuring the quality in any health care system. Patient satisfaction has positive effect on clinical improvement, patient adherence and retention, job satisfaction and appropriate clinical care by physicians [1-3]. On the other hand, mismatch between patient expectation and the service they received leads dissatisfaction. Patient satisfaction towards clinical laboratory service

\footnotetext{
*Correspondence: yih2000ho@gmail.com

${ }^{2}$ Department of Public Health, Debre Markos University, Debre Markos, Ethiopia

Full list of author information is available at the end of the article
}

is influenced by the quality of service and professionalism of the staff, provision of adequate information to collect specimen and when and how to receive laboratory results, waiting time to receive laboratory results, availability of ordered laboratory tests, cleanness of the laboratory room, location of laboratory room, availability and accessibility of latrine [4-9].

Patient's satisfaction on laboratory services has not yet exhaustively studied in Ethiopia. Thus, this study aimed to investigate patient satisfaction with clinical laboratory services and associated factors among adult patients attending outpatient departments at Debre Markos referral hospital, Northwest Ethiopia. 


\section{Main text \\ Methods}

\section{Study design, area and period}

An institution based cross-sectional study was conducted from April 09 to 16, 2019 at Debre Markos Referral Hospital. The average number of patients monthly treated in the hospital as an outpatient was 5658 from the three wards internal medicine (2100), surgery (1800) and Gynecology/Obstetrics (1758) respectively [10].

\section{Population and eligibility criteria}

The source population was all adult patients ( $\geq 18$ years) visiting laboratory service from internal medicine, surgery, Gynecology/Obstetrics departments at Debre Markos Referral Hospital. The study population was all adult patients ( $\geq 18$ years) visiting laboratory service from internal medicine, surgery and Gynecology/Obstetrics departments at Debre Markos Referral Hospital during the data collection period. All adult patients at the internal medicine, surgery and Gynecology/Obstetrics outpatient departments who were requested for clinical chemistry, hematology, parasitological and urine analysis tests were included in the study. However, patients who had mental illness and hearing impairments were excluded from the study.

\section{Sample size determination and sampling procedure}

The required sample size was calculated using a single population proportion formula;

$$
\mathrm{n}=\frac{(\mathrm{z} \alpha / 2)^{2} \mathrm{p}(1-\mathrm{p})}{\mathrm{d}^{2}}
$$

\section{Assumptions}

$\mathrm{n}=$ required sample size, $\mathrm{Z}=$ critical value for normal distribution at $95 \%$ confidence level (1.96), $d=0.05$ (5\% margin of error), $\mathrm{P}=63.3 \%$ (proportion of patients satisfied with laboratory service) [11] and an estimated nonresponse rate of $10 \%$. The final calculated sample size for this study was 391. Systematic random sampling technique was used to select study participants with $\mathrm{k}$-values 3, 4, 4 respectively. Proportional allocation to population size (170 from Internal medicine, 112 from Surgery, and 109 from Gynecology/Obstetrics outpatient departments) was employed.

\section{Data collection procedure}

Data were collected using a pre-tested and structured interviewer administered questionnaire. The questionnaire was prepared in English and translated to Amharic, then back to English to check for its consistency. The questionnaire contains satisfaction indicators which were related to socio-demographic characteristics of the patients and different dimensions of laboratory services such as waiting time (turnaround time), availability of requested laboratory tests, convenience of service hours, and type of laboratory visit, privacy, respect, courtesy and confidentiality. The study participants were asked to rate each aspects of the laboratory service on five point liker scale $(1=$ Very Dissatisfied, $2=$ Dissatisfied, $3=$ Neutral, $4=$ Satisfied, $5=$ Very satisfied). Exit interview of patients was carried out.

To assure the data quality, two diploma laboratory technicians and one BSc laboratory professional were recruited as data collectors and supervisor, respectively. In addition, training regarding the study objectives and data collection process was given for data collectors and supervisor for 2 days. Moreover, the questionnaire was pretested among 5\% of the sample size at Finoteselam hospital. Furthermore, intensive supervision was done by supervisor and principal investigators throughout the data collection period.

\section{Study variables}

The dependent variable of this study was patient satisfaction. Patient satisfaction with laboratory services was defined as the patient's opinion of the care received from the institution and is acknowledged as an outcome indicator of the quality of health care. i.e. $\geq$ mean value $=$ Satisfied and $<$ mean value $=$ Dissatisfied [7].

The independent variables were: Socio-demographic characteristics (age, gender, level of education, marital status, occupation, income and residence), waiting time to get service, availability of requested lab tests, convenience of service hours, confidentiality of lab results, improvement of service from time to time, queue process to get service, availability of service providers at their job, missing results, cost of laboratory service, location of laboratory, hospitality of laboratory professionals to patient, cleanness of latrine, needle stick attempted, and availability of equipment.

\section{Data processing and analysis}

Data were cleaned, coded and entered using Epi-Data software Version 4.2 and analyzed using SPSS Version 23. Binary logistic regression was employed. In the bivariable analysis, variables with p-value $<0.25$ were fitted into the multivariable model. Finally, adjusted odds ratios with their 95\% confidence intervals were estimated to assess the strength of association, and variables with p-value $<0.05$ were considered statistically significant factors. 


\section{Results}

Socio-demographic characteristics of the study participants A total of 391 laboratory service users were included in the study, resulting in a response rate of $100 \%$. About 244 (57.3\%), and more than two-third (68.7\%) of the respondents were females and married respectively. The mean age of participants was $36.9( \pm 14.08)$ years with a range of 18-75 years. Nearly half of the respondents were unable to read and write $(47.8 \%)$ and almost onethird (30.4\%) of them were housewives. Majority (86.2\%) had reported that they earn an average family monthly income of more than 500 Ethiopian Birr. Almost half of the participants resided in rural areas (Table 1).

\section{General service parameters and patients' satisfaction towards clinical laboratory services}

The overall patient satisfaction on laboratory services was determined by taking mean score and above for 16 variables that were utilized to reflect satisfaction. Nearly half $(48.3 \%)$ of patients were satisfied with the general clinical laboratory services provided. Majority of the study participants $(89.5 \%)$ had got the service with payment. Majority $(83.4 \%)$ of the respondents have got all the requested laboratory tests that the clinicians ordered. Nearly half (44\%) of the patients were first time service users at the hospital laboratory. When the respondents were asked if they come again to get services at the hospital laboratory, almost all (96.2\%) of them were interested to come again. Among the reason to come again the same hospital laboratory to get service were: good quality of service (26.3\%), preferred service providers $(21.3 \%)$, availability of many services $(21.0 \%)$, cheap service fee $(12.3 \%)$, get service early $(9.7 \%)$ and convenience of working hour (4.6\%). In contrary to the previous, the reasons for not coming again to the same hospital to get laboratory services were long waiting time. Regarding the turnaround time to get results, the majority $(82.4 \%)$ responded that they wait more than $1 \mathrm{~h}$ and nearly two-third (67\%) of participants had one vein puncture attempt (Table 2).

Table 1 Socio-demographic characteristics of hospital laboratory service users at Debre Markos referral hospital, Northwest Ethiopia, 2019 ( $n=391)$

\begin{tabular}{|c|c|c|c|}
\hline Variables & Category & Frequency & Percentage \\
\hline \multirow[t]{2}{*}{ Sex } & Male & 167 & 42.7 \\
\hline & Female & 224 & 57.3 \\
\hline \multirow[t]{5}{*}{ Age in years } & $18-27$ & 123 & 31.4 \\
\hline & $28-37$ & 114 & 29.2 \\
\hline & $38-47$ & 57 & 14.6 \\
\hline & $48-57$ & 54 & 13.8 \\
\hline & $\geq 58$ & 43 & 11.0 \\
\hline \multirow[t]{5}{*}{ Educational status } & Unable to read and write & 187 & 47.8 \\
\hline & Able to read and write & 31 & 7.9 \\
\hline & Grade 1-8 & 53 & 13.6 \\
\hline & Grade 9-12 & 53 & 9.0 \\
\hline & Diploma and above & 85 & 21.7 \\
\hline \multirow[t]{4}{*}{ Marital status } & Married & 268 & 68.6 \\
\hline & Single & 70 & 17.8 \\
\hline & Divorced & 25 & 6.4 \\
\hline & Widowed & 28 & 7.2 \\
\hline \multirow[t]{6}{*}{ Occupation } & Student & 70 & 17.9 \\
\hline & Housewife & 119 & 30.4 \\
\hline & No employment & 20 & 5.2 \\
\hline & Merchant & 48 & 12.3 \\
\hline & Government worker & 33 & 8.4 \\
\hline & Farmer & 101 & 25.8 \\
\hline \multirow{2}{*}{$\begin{array}{l}\text { Average family monthly income (in Ethiopian } \\
\text { Birr) }\end{array}$} & $\leq 500$ & 54 & 13.8 \\
\hline & $>500$ & 337 & 86.2 \\
\hline \multirow[t]{2}{*}{ Residence } & Rural & 201 & 51.4 \\
\hline & Urban & 190 & 48.6 \\
\hline
\end{tabular}


Table 2 General service parameters of Hospital laboratory service users at Debre Markos referral hospital, Northwest Ethiopia, 2019 ( $n=391$ )

\begin{tabular}{|c|c|c|}
\hline Variable & Frequency & Percent (\%) \\
\hline \multicolumn{3}{|l|}{ Service payment } \\
\hline Payment & 350 & 89.5 \\
\hline Free & 41 & 10.5 \\
\hline \multicolumn{3}{|l|}{ Do you know this laboratory before? } \\
\hline Yes & 219 & 56.0 \\
\hline No & 172 & 44.0 \\
\hline \multicolumn{3}{|l|}{ Improvement of service $(n=219)$} \\
\hline Yes & 145 & 66 \\
\hline No & 74 & 34 \\
\hline \multicolumn{3}{|l|}{ Turnaround time } \\
\hline$<30 \min$ & 17 & 4.3 \\
\hline $30 \mathrm{~min}-1 \mathrm{~h}$ & 52 & 13.3 \\
\hline$>1 \mathrm{~h}$ & 322 & 82.4 \\
\hline \multicolumn{3}{|l|}{ Will you come again to the hospital laboratory } \\
\hline Yes & 376 & 96.2 \\
\hline No & 15 & 3.8 \\
\hline \multicolumn{3}{|l|}{ Reason to decide to come again } \\
\hline Convenient opening hour & 18 & 4.6 \\
\hline Get the service early & 38 & 9.7 \\
\hline Good quality service & 103 & 26.4 \\
\hline Availability of many services & 82 & 21.0 \\
\hline Cheaper service fee & 48 & 12.3 \\
\hline Preferred service provider here & 83 & 21.2 \\
\hline Others & 4 & 1.0 \\
\hline $\begin{array}{l}\text { Reason to decide not to come again }(n=15) \\
\text { long waiting time }\end{array}$ & 15 & 3.8 \\
\hline \multicolumn{3}{|l|}{ Needle stick attempted to draw blood } \\
\hline One vein puncture & 262 & 67.0 \\
\hline Two vein puncture & 88 & 22.5 \\
\hline Three vein puncture & 30 & 7.7 \\
\hline Four or more vein puncture & 11 & 2.8 \\
\hline \multicolumn{3}{|c|}{ Place in blood drawing room to put personal thing } \\
\hline Yes & 148 & 37.9 \\
\hline No & 243 & 62.1 \\
\hline \multicolumn{3}{|l|}{ Occasion of missing results } \\
\hline Yes & 65 & 16.6 \\
\hline No & 326 & 83.4 \\
\hline \multicolumn{3}{|c|}{ Information given on how to decrease possible bruise } \\
\hline Yes & 245 & 62.7 \\
\hline No & 146 & 37.3 \\
\hline
\end{tabular}

\section{Factors affecting the level of patients' satisfaction towards clinical laboratory services}

In the bivariable analysis, educational status of respondents, occupation, residence, occasions of missing laboratory results, information to decrease possible bruise, place to put personal thing, convenience of opening hour were found to be associated with patient satisfaction on clinical laboratory services.

These factors were further analyzed using multivariable logistic regression by enter method. The results of multivariable logistic regression analysis showed that the educational level, missing of laboratory results, and availability of place in blood drawing room to put personal things were found to have a statistically significant association with the overall satisfaction of patients toward clinical laboratory services.

The likelihood of patient satisfaction on clinical laboratory services was 2.1 times more likely in patients who had no occasion of missing laboratory results as compared with who had occasion of missing results $(\mathrm{AOR}=2.10,95 \%$ CI 1.13, 3.83).

On the other hand, patients who were able to read and write and who had diplomas and above educational level were less likely to be satisfied with the laboratory services compared to those who were not able to read and write $(\mathrm{AOR}=0.41,95 \% \mathrm{CI} 0.18,0.92$ and $\mathrm{AOR}=0.38,95 \% \mathrm{CI}$ $0.15,0.96)$ respectively. Similarly, patients who said no place in the laboratory to put personal things were less likely to be satisfied with the laboratory service compared to their counterparts $(\mathrm{AOR}=0.34,95 \%$ CI $0.21,0.54)$ (Table 3).

\section{Discussion}

Patient centered care is one of the six domains of health care quality developed by World Health Organization. The aim of this study was to examine the satisfaction of patients with clinical laboratory services and its associated factors among adult patients attending outpatient departments at Debre Markos referral hospital, Northwest Ethiopia.

The overall client satisfaction towards medical laboratory services in study area was $48.3 \%$. This is in line with the findings of the study at Amhara Region, Northwest Ethiopia, 52.6\% [12]. The possible explanation for the low satisfaction rate might be due to excess flow of patients to the laboratory as Debre Markos referral hospital is the only referral hospital used for East Gojjam and West Gojjam, Awi, West Wollega and South Wollo Zones. But, the current finding is slightly lower than a report from a study conducted in a teaching hospital in Addis Ababa (59.7\%) [4] and Nekemte Hospital, Oromia Region (60.4\%) [13]. The other studies from Eastern Ethiopia (87.6\%) [8], and Southern Ethiopia (90.8\%) [14] are much higher than the current study. This might be attributed to a difference in study area, period and patient flow.

The findings of this study showed that patients who were able to read and write and who had diplomas and above educational level were less likely to be satisfied with the laboratory service compared to those who 
Table 3 Factors associated with patient satisfaction towards clinical laboratory service among adult patients attending outpatient departments at Debre Markos referral hospital, $2019(\mathrm{n}=391)$

\begin{tabular}{|c|c|c|c|c|}
\hline \multirow[t]{2}{*}{ Variable } & \multicolumn{2}{|l|}{ Satisfaction } & \multirow[t]{2}{*}{ Crude OR $(95 \% \mathrm{Cl})$} & \multirow[t]{2}{*}{ Adjusted OR $(95 \% \mathrm{Cl})$} \\
\hline & Satisfaction n (\%) & Dissatisfaction n (\%) & & \\
\hline \multicolumn{5}{|l|}{ Education } \\
\hline Unable to read and write & $79(20.25)$ & $108(27.6 \%)$ & 1.00 & 1.00 \\
\hline Able to read and write & $13(3.3 \%)$ & $18(4.6 \%)$ & $0.30(0.19,0.56)$ & $0.41(0.18,0.92)$ \\
\hline Grade 1-8 & $23(5.9 \%)$ & $30(7.7 \%)$ & $0.30(0.14,0.74)$ & $0.52(0.14,3.26)$ \\
\hline Grade 9-12 & $15(3.8 \%)$ & $20(5.1 \%)$ & $0.34(0.17,0.67)$ & $0.47(0.20,1.11)$ \\
\hline Diploma and above & $59(15.1 \%)$ & $26(6.6 \%)$ & $0.33(0.15,4.10)$ & $0.38(0.15,0.96)$ \\
\hline \multicolumn{5}{|l|}{ Place to put personnel things } \\
\hline Yes & $52(13.3 \%)$ & $96(24.6 \%)$ & 1.00 & 1.00 \\
\hline No & $137(35.0 \%)$ & $106(27.1 \%)$ & $0.42(0.28,0.64)$ & $0.34(0.21,0.54)$ \\
\hline \multicolumn{5}{|l|}{ Occasion of missing results } \\
\hline Yes & $42(10.7 \%)$ & $23(5.9 \%)$ & 1.00 & 1.00 \\
\hline No & $147(45.8 \%)$ & $179(37.6 \%)$ & $2.2(1.30,3.90)$ & $2.10(1.13,3.83)$ \\
\hline
\end{tabular}

cannot able to read and write, which is supported by similar study conducted in Tikur Anbesa Specialized Hospital, Addis Ababa [4] and Sidama Zone, Southern Ethiopia [14]. This might occur due to the fact that patients who were educated expect more professionalism from service providers and also quality service and infrastructures.

Those patients who reported no place available in the laboratory room to put personal things were less likely to be satisfied with the laboratory service compared their counterparts. It is comparable with a study conducted in Tikur Anbesa Specialized Hospital patients [4]. The absence of place in the laboratory room might lead patients to think about their possession decreasing their satisfaction on the service they received.

The odds of patients who had no occasion of missing laboratory results were 2.1 times more likely to be satisfied with the service than those who had occasion of missing results. This may be due to patients were susceptible to unethical additional service fee and long waiting time to get results with associated delay in getting the clinical health provider service. But, there was no similar significant association in other similar studies the researchers tried to search for even though the percentage of patients who complains missing laboratory results was $16.6 \%$ in this study, which is nearly equivalent to a similar study done in Nigeria (17.9\%) [15].

In conclusion, the overall patients' satisfaction towards clinical laboratory services was low. The educational level, missing of laboratory results, and availability of place in blood drawing room to put personal things were found to have a statistically significant association with the overall satisfaction of patients towards clinical laboratory services. The hospital administration and laboratory department in Debre Markos referral hospital should strengthen their effort to improve patient satisfaction focusing on educational status of patients, missing laboratory results, and the availability of places to put personal things in the blood drawing room. Proper service availability and readiness plan should be prepared and implemented to satisfy patients towards the laboratory services rendered at Debre Markos referral hospital.

\section{Limitations of the study}

This study has the following limitations: the evidence of the study would have been enriched if it was supported by qualitative method. The perspectives of clinicians, service providers, and patients admitted in the hospital were not included. Face-to-face interview of respondents at the hospital might have exposed the study for social desirability bias.

\section{Abbreviations \\ SPSS: statistical package for social sciences; Cl: confidence interval; COR: crude odds ratio; AOR: adjusted odds ratio.}

\section{Acknowledgements \\ Authors would like to thank Debre Markos referral hospital, supervisor, data collectors and study participants.}

\section{Authors' contributions}

AA and YAB conceived, designed the study, supervised the data collection, and performed the data analysis, interpretation of the result, and drafting the manuscript. Both authors read and approved the final manuscript.

Funding

Not applicable.

Availability of data and materials

All data generated or analyzed during this study are included in this published article and its additional information files. 


\section{Ethics approval and consent to participate}

The study was approved by Ethical Review Committee of College of Health Science, Debre Markos University. Permission letter was obtained from Debre Markos referral Hospital. The participants enrolled in the study were informed about the study objectives, expected outcomes, benefits and the risks associated with it. Written consent was taken from the participants before the interview.

\section{Consent for publication}

Not applicable.

\section{Competing interests}

The authors declare that they have no competing interests.

\section{Author details}

${ }^{1}$ Debre Markos Referral Hospital, Debre Markos, Ethiopia. ${ }^{2}$ Department of Public Health, Debre Markos University, Debre Markos, Ethiopia.

Received: 10 July 2019 Accepted: 10 August 2019

Published online: 19 August 2019

\section{References}

1. Zgierska A, Rabago D, Miller MM. Impact of patient satisfaction ratings on physicians and clinical care. Patient Prefer Adherence. 2014;8:437-46.

2. Dubina MI, O'Neill JL, Feldman SR. Effect of patient satisfaction on outcomes of care. Expert Rev Pharmacoecon Outcomes Res. 2009;9(5):393-5.

3. Prakash DB. Patient satisfaction. J Cutan Aesthet Surg. 2010;3(3):151-5. https://doi.org/10.4103/0974-2077.74491.

4. Abera RG, Abota BA, Legese MH, Negesso AE. Patient satisfaction with clinical laboratory services at Tikur Anbessa specialized hospital, Addis Ababa, Ethiopia. Patient Prefer Adherence. 2017;11:1181.

5. Bekele MTS. Assessment of patients' satisfaction towards general medical laboratory services at Shenen Gibe Public Hospital, Jimma Town, South West Ethiopia. J Health Med Nurse. 2016;31:78-84.
6. Georgieva E, Tsankova G, Kaludova V, Ermenlieva N. Patients satisfaction with laboratory services at selected medical-diagnostic laboratories in Varna. J IMAB Ann Proc Sci Pap. 2014;20(2):500-1.

7. Mindaye T, Taye B. Patients satisfaction with laboratory services at antiretroviral therapy clinics in public hospitals, Addis Ababa, Ethiopia. BMC Res Notes. 2012;5(1):184.

8. Teklemariam Z, Mekonnen A, Kedir H, Kabew G. Clients and clinician satisfaction with laboratory services at selected government hospitals in eastern Ethiopia. BMC Res Notes. 2013;6(1):15.

9. Thomas J. Patients' satisfaction with clinical laboratory services in a secondary health care facility, ondo west local government area, Nigeria. 2015.

10. Debre Markos Referral Hospital. Panning, monitoring and evaluation department. 2019.

11. Geleto A, Baraki N, Atomsa GE, Dessie Y. Job satisfaction and associated factors among health care providers at public health institutions in Harari region, eastern Ethiopia: a cross-sectional study. BMC Res Notes. 2015;8(1):394.

12. Bogale AL, Kassa HB, Ali JH. Patients' perception and satisfaction on quality of laboratory malaria diagnostic service in Amhara Regional State, North West Ethiopia. Malaria J. 2015;14(1):241.

13. Tadele G, Ejeta E, Desalegn M, Abere S, Elias K. Patients satisfaction on clinical laboratory services at Nekemte Referral Hospital, Oromia, Ethiopia. Food Sci Qual Manag. 2014;30:25-30.

14. Belay M, Abrar S, Bekele D, Daka D, Derbe M, Birhaneselassie M. HIV/ AIDS Patients' satisfaction on ART laboratory service in selected governmental hospitals, Sidamma Zone, southern Ethiopia. Sci J Public Health. 2013;1:85.

15. Iliyasu Z, Abubakar I, Abubakar S, Lawan U, Gajida A. Patients' satisfaction with services obtained from Aminu Kano Teaching Hospital, Kano, Northern Nigeria. Niger J Clin Pract. 2010;13(4):371-8.

\section{Publisher's Note}

Springer Nature remains neutral with regard to jurisdictional claims in published maps and institutional affiliations.
Ready to submit your research? Choose BMC and benefit from

- fast, convenient online submission

- thorough peer review by experienced researchers in your field

- rapid publication on acceptance

- support for research data, including large and complex data types

- gold Open Access which fosters wider collaboration and increased citations

- maximum visibility for your research: over 100M website views per year

At BMC, research is always in progress.

Learn more biomedcentral.com/submissions 